\title{
Mutant pfcrt "SVMNT" haplotype and wild type pfmdr1 "N86" are endemic in Plasmodium vivax dominated areas of India under high chloroquine exposure
}

Prashant K Mallick', Hema Joshi', Neena Valecha', Surya K Sharma², Alex Eapen ${ }^{3}$, Rajendra M Bhatt ${ }^{4}$, Harish C Srivastava ${ }^{5}$, Patrick L Sutton ${ }^{6}$, Aditya P Dash ${ }^{1,8}$ and Virendra K Bhasin ${ }^{7^{*}}$

\begin{abstract}
Background: Chloroquine resistance (CQR) phenotype in Plasmodium falciparum is associated with mutations in pfcrt and pfmdr-1 genes. Mutations at amino acid position 72-76 of pfcrt gene, here defined as pfcrt haplotype are associated with the geographic origin of chloroquine resistant parasite. Here, mutations at 72-76 and codon 220 of pfcrt gene and N86Y pfmdr-1 mutation were studied in blood samples collected across 11 field sites, inclusive of high and low P. falciparum prevalent areas in India. Any probable correlation between these mutations and clinical outcome of CQ treatment was also investigated.
\end{abstract}

Methods: Finger pricked blood spotted on Whatman No.3 papers were collected from falciparum malaria patients of high and low P. falciparum prevalent areas. For pfcrt haplotype investigation, the parasite DNA was extracted from blood samples and used for PCR amplification, followed by partial sequencing of the pfcrt gene. For pfmdr-1 N86Y mutation, the PCR product was subjected to restriction digestion with AfIIII endonuclease enzyme.

Results: In 240 P. falciparum isolates with reported in vivo CQ therapeutic efficacy, the analysis of mutations in pfcrt gene shows that mutant SVMNT-S (67.50\%) and CVIET-S (23.75\%) occurred irrespective of clinical outcome and wild type CVMNK-A (7.91\%) occurred only in adequate clinical and parasitological response samples. Of 287 P. falciparum isolates, SVMNTS 192 (66.89\%) prevailed in all study sites and showed almost monomorphic existence (98.42\% isolates) in low P. falciparum prevalent areas. However, CVIETS-S (19.51\%) and CVMNK-A (11.84\%) occurrence was limited to high P. falciparum prevalent areas. Investigation of pfmdr-1 N86Y mutation shows no correlation with clinical outcomes. The wild type N86 was prevalent in all the low P. falciparum prevalent areas (94.48\%). However, mutant N86Y was comparably higher in numbers at the high $P$. falciparum prevalent areas (42.76\%).

Conclusions: The wild type pfcrt gene is linked to chloroquine sensitivity; however, presence of mutation cannot explain the therapeutic efficacy of CQ in the current scenario of chloroquine resistance. The monomorphic existence of mutant SVMNT haplotype, infer inbreeding and faster spread of CQR parasite in areas with higher $P$. vivax prevalance and chloroquine exposure, whereas, diversity is maintained in pfcrt gene at high $P$. falciparum prevalent areas.

\footnotetext{
* Correspondence: virendrabhasin@gmail.com

${ }^{7}$ Department of Zoology, University of Delhi, Delhi 110007, India

Full list of author information is available at the end of the article
} 


\section{Background}

Widespread Plasmodium falciparum chloroquine resistance (CQR) continues to pose a great challenge to malaria control efforts [1]. CQR is associated with single nucleotide polymorphisms (SNPs), which cause nonsynonymous amino acid substitutions in the P. falciparum chloroquine resistance transporter ( $p f c r t$ ) gene. As a result, the $p f c r t$ gene is commonly used in epidemiological studies to characterize chloroquine treatment failure and ultimately monitor the emergence of drug resistance within endemic regions [2]. The replacement of a lysine (K) by a threonine (T) at codon 76 of the pfcrt gene seems to be a hallmark of CQR worldwide; both in vitro and in vivo tests suggest its use as an epidemiological tool for large scale studies of CQR in the field [3,4]. Twenty additional SNP's have been identified in the $p f c r t$ gene from CQR field isolates, which may be due to selective pressure driving the population structure [5]. Two major haplotypes defined by specific mutations at amino acid positions 72-76 of pfcrt, CVIET and SVMNT, are associated with the geographic origin of CQR [6]. The CVIET haplotype is predominantly found in Southeast Asia and Africa, whereas the SVMNT haplotype is characteristic of South America, Papua New Guinea (PNG) [7], and the Philippines [8]. However, the CVIET haplotype has been observed in South America [9-11] and SVMNT haplotype in Southeast Asia [12]. Most African isolates share the CVIET haplotype of Southeast Asia, and it is hypothesized that this haplotype was imported through the Indian subcontinent [13]. Chloroquine-sensitive (CQS) strains are characterized by the CVMNK haplotype, irrespective of geographic origin. In India, the first $P$. falciparum chloroquine resistant case was reported in 1973 [14] and subsequently swept throughout the country [15]. The most prevalent $p f c r t$ haplotype identified in India is SVMNT, although CVIET has also been observed [16-18]. A recent study reported that the SVMNT haplotype found in central India is closely related to the SVMNT genotype found in PNG [19], but it has yet to be determined if these two haplotypes have independent origins.

Similarly, SNPs in the P. falciparum multidrug resistance-1 (pfmdr-1) gene have been associated with reduced susceptibility to chloroquine treatment. Specifically, a SNP causing a nonsynonymous amino acid substitution at amino acid position 86, replaces the wild type asparagine $(\mathrm{N})$ with a resistant tyrosine $(\mathrm{Y})$ [20-22]. Most studies, including those performed in India, observe weak associations between $p f m d r-1$ mutations and parasite that are CQR $[4,16,17,23]$.

Historically, $P$. vivax has been the principal malaria species in India; however, during the past two decades the incidence of $P$. falciparum has more than doubled; this has been attributed to a rise in chloroquine resistance across India [15]. Chloroquine resistance may have been exacerbated by misdiagnosis and consequently improper anti-malarial drug treatment, as chloroquine $(\mathrm{CQ})$ is the first-line drug for vivax malaria in India [24]. Given that $P$. falciparum causes more severe and complicated forms of malaria, a resurgence of this parasite is alarming. Limited data is available on the distribution of P. falciparum resistant genotypes in regions typically dominated by $P$. vivax. Also, there is an overall lack of information on how these genetic haplotypes correlate with clinical resistance to CQ in India. Due to this, it is difficult to track CQR throughout India and nearly impossible to predict potential outbreaks of resistant parasites. This is a serious cause for concern, especially in regions of India where vivax malaria is the dominant species. During this study, CQR was monitored on molecular level by investigating the distribution of $p f c r t$ haplotypes (concatenating mutations at codons 72-76 and codon 220) and the pfmdr-1 N86Y mutation across 11 field sites. Both high and low $P$. falciparum endemic sites in India were included to account for the impact of transmission intensity on the appearance of resistance and sensitive phenotypes with respect to these markers. Widespread parasite resistance to chloroquine was observed in India, while sensitive parasites appeared mostly in high $P$. falciparum endemic sites, like Chhattisgarh, Jharkhand, and Orissa [15].

\section{Methods}

\section{Selection of isolates}

The samples included in this study were collected from two independent studies: (i) 240 samples from a CQ therapeutic efficacy trial occurring in eight different field sites of varying $P$. falciparum prevalence (sites 1-8, below) and (ii) 47 samples collected by random malaria surveys in 3 additional sites (site 9-11, below). All of the samples were collected between 2002-2006. In the CQ therapeutic efficacy trial, patients were classified according to World Health Organization guidelines as: adequate clinical and parasitological response (ACPR), early treatment failure (ETF), and late treatment failure (LTF). All information about this clinical trial has been described elsewhere [25-27]. The Ethics Committee of National Institute of Malaria Research (NIMR) approved this study protocol. All individuals or the parents/guardians of children gave written informed consent before inclusion in the study.

\section{Study sites}

The proportion of $P$. vivax and $P$. falciparum varies in different parts of India. The study sites below represent the variable profiles of malaria transmission in India (Figure 1), classified into two groups according to $P$ falciparum transmission. First, regions with high P. falciparum transmission: the Northeastern (Assam, W. Bengal), Eastern (Orissa, 


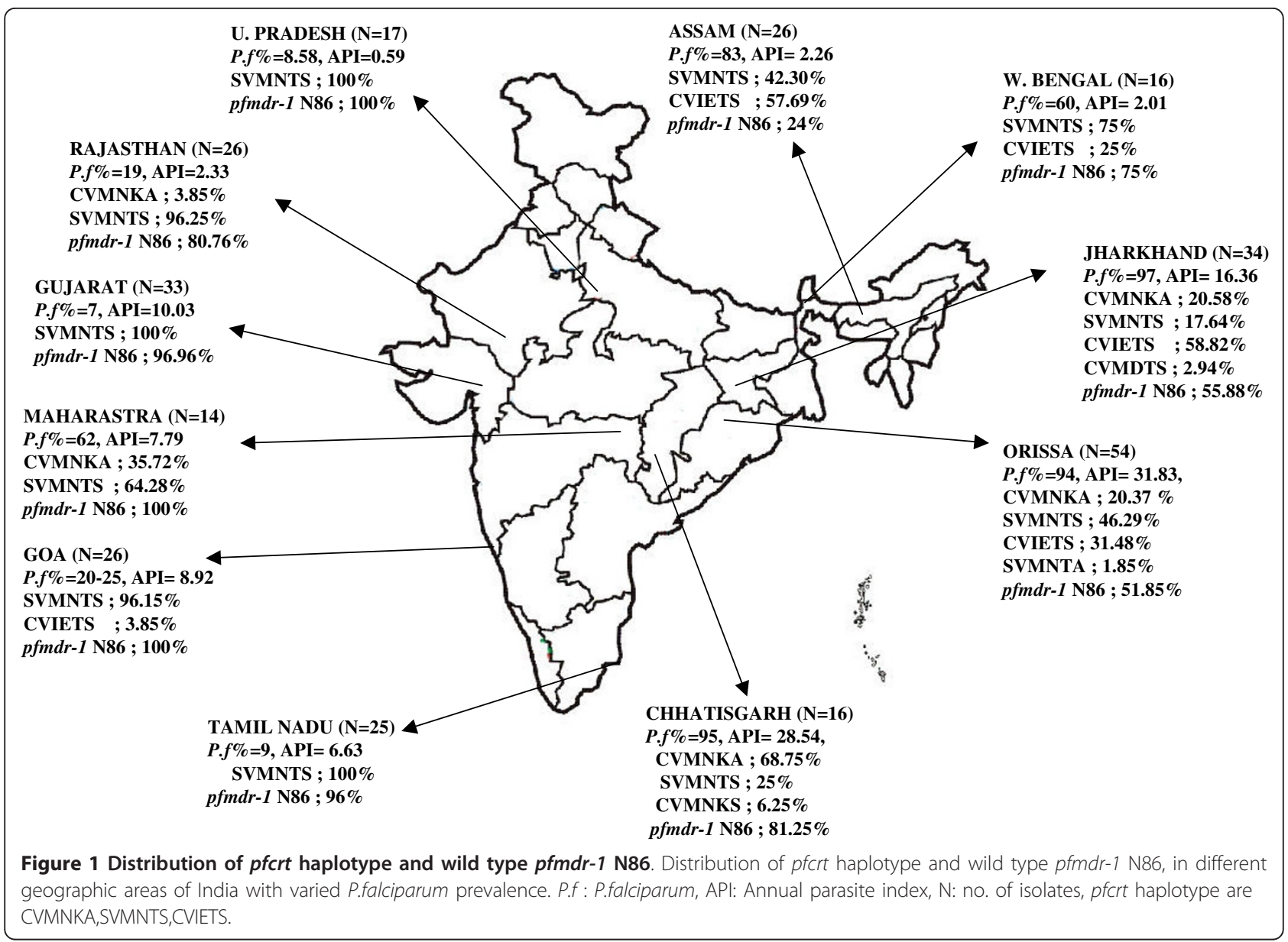

Jharkhand), Western (Maharastra), and Central (Chhattisgarh) regions of India. Second, regions with low P. falciparum transmission: North Central (UttarPradesh), Western (Rajasthan, Gujarat, Goa), and Southern (Tamil Nadu) part of India. These regions are described in detail below.

1. Orissa, Eastern coastal state: Sundergarh district (latitudes $21^{\circ} 35^{\prime} \mathrm{N}$ to $22^{\circ} 35^{\prime} \mathrm{N}$, and longitude $83^{\circ} 32^{\prime} \mathrm{E}$ to $85^{\circ} 22^{\prime} \mathrm{E}$ ) presents ideal ecological conditions for malaria, with undulating uplands intersected by forested hills, rocky streams, and paddy fields. This state contributes $23 \%$ to the country's malaria burden. In general, malaria endemicity ranges from meso- to hyperendemic malaria, with annual transmission. Sample collection from this field site occurred during year 2003. During this time, $P$. falciparum was the dominant infecting species, accounting for approximately $94 \%(n=56331)$ of all recorded malaria infections.

2. Assam, North-Eastern state: Kamrup district (latitudes $25^{\circ} 46^{\prime} \mathrm{N}$ to $26^{\circ} 49^{\prime} \mathrm{N}$, and longitudes $90^{\circ} 48^{\prime} \mathrm{E}$ to $91^{\circ}$ $50^{\prime} \mathrm{E}$ ) is predominantly forest (1166.94 sq km of the district). Assam is near $(80-100 \mathrm{~km})$ the international borders of Myanmar, China and shares international borders with Bangladesh and Bhutan. The district had moderate and perennial malaria transmission with approximately $83 \%(\mathrm{n}=4645)$ due to $P$. falciparum of all malaria cases recorded in year 2002 .

3. Jharkhand, Eastern state: Simdega district (latitudes $20^{\circ} 10^{\prime} \mathrm{N}$ to $20^{\circ} 40^{\prime} \mathrm{N}$, and longitudes $84^{\circ} \mathrm{E}$ to $84^{\circ} 34^{\prime} \mathrm{E}$ ) covered with forested area (1194.50 sq $\mathrm{km}$ of the district) is highly endemic for P. falciparum malaria. A total of $97 \%$ $(\mathrm{n}=8,618)$ of the recorded malaria cases in year 2006 were $P$. falciparum infected, and it represented approximately $7 \%$ of the country's total malaria burden in same year.

4. West Bengal, Eastern state: Darjleeng district (latitude $27^{\circ} 42^{\prime} \mathrm{N}$ and longitude $88^{\circ} 16^{\prime} \mathrm{E}$ ) is covered with forested hills, as it is located in the foothills of Himalayas. The district shares an international border with Nepal, Bangladesh, and Bhutan. Malaria transmission in the district is moderate, with seasonal malaria transmission of malaria. During the sample collection year 2003, P. falciparum comprised approximately 60\% ( $\mathrm{n}=2157)$ of malaria infections in this region.

5. Goa, Western coast: Panaji (latitudes $15^{\circ} \mathrm{N}$ and longitude $73^{\circ} \mathrm{E}$ ), in the North Goa district, is an urban 
area surrounded by plains. It is a tourist destination with much ongoing construction work, which provides a higher rate of human migration and promotes a niche for malaria transmission. $P$. vivax is the predominant malaria species in Panaji, however the percentage of $P$. falciparum malaria has increased up to $20-25 \%$ in last 5 years. The field site record indicates that $P$. falciparum comprised $20.5 \%(\mathrm{n}=1298)$ of all the malaria cases in the year 2004.

6. Gujarat, Western state: Anand district (latitude $22^{\circ}$ $57^{\prime} \mathrm{N}$ and longitude $72^{\circ} 93^{\prime} \mathrm{E}$ ) is a rural area with plains. Anand is prone to malaria epidemics, but typically has low and seasonal transmission. $P$. vivax is the predominant malaria species in this district; only $7 \%(n=1358)$ of the malaria was attributed to P. falciparum infection in the year 2005.

7. Rajasthan, Western state: Udaipur district (latitude $24^{\circ} 35^{\prime} \mathrm{N}$ and longitude $73^{\circ} 41^{\prime} \mathrm{E}$ ) is located in the plains and has low and seasonal transmission. In year 2003, $P$. falciparum contributed only $19 \%(\mathrm{n}=1151)$ of the total malaria burden within this district.

8. Tamil Nadu, Southern coastal state: Rameswarum Island (latitude $9^{\circ} 22^{\prime} \mathrm{N}$ and longitude $78^{\circ} 52^{\prime} \mathrm{E}$ ) in Ramanathapuram district of Tamil Nadu is a pilgrimage site, where human travel from various parts of country is a daily routine. Rameswarum Island is an endemic region for $P$. vivax malaria and has perennial transmission. Samples were collected in year2004, and only 9\% ( $\mathrm{n}=$ 359 ) of the malaria burden was attributed to P. falciparum in same year.

9. Chhattisgarh, Central state: Kanker district, (latitudes $20^{\circ} 6^{\prime} \mathrm{N}$ to $20^{\circ} 24^{\prime} \mathrm{N}$, and longitudes $80^{\circ} 48^{\prime} \mathrm{E}$ to $81^{\circ}$ $\left.48^{\prime} \mathrm{E}\right)$ have small hilly pockets throughout the district. Malaria endemicity is high, with annual transmission. In sample collection year 2006, P. falciparum malaria accounted for approximately 95\% ( $n=20573)$ of the total malaria burden in the same region.

10. Maharastra, Western state: Gadchiroli district (latitude $20^{\circ} 6^{\prime} \mathrm{N}$ and longitude $80^{\circ} \mathrm{E}$ ) in the state of Maharastra is covered with dense forest and hills. The forest covers approximately $75.9 \%$ of the geographical areas of the district. Malaria endemicity is high, with annual transmission. In year 2002, P. falciparum accounted for approximately $62 \%(n=4732)$ of the malaria burden in the district.

11. Uttar Pradesh, North Central State: Gautam Budh Nagar district (latitude $28^{\circ} 34^{\prime} \mathrm{N}$ and longitude $77^{\circ} 33^{\prime} \mathrm{E}$ ) is an industrial area, located in the plains, heavily populated with migrant labourers from across the country. Malaria endemicity is low and seasonal, with $P$. vivax accounting for the highest burden of malaria within this region. In year 2002, P. falciparum only accounted for approximately $9 \%(\mathrm{n}=17)$ of the total malaria cases recorded in the district.

\section{Genomic DNA isolation and PCR amplification}

Genomic DNA was extracted from blood spots collected on Whatman No.3 filter paper, using a QIAamp DNA Blood Mini Kit (Qiagen, Hilden, Germany).

pfcrt and pfmdr-1 genes were amplified from extracted DNA by nested PCR assays. Primary and nested PCR assays were performed in a $20 \mu \mathrm{l}$ volume reaction with $0.75 \mathrm{U}$ of Taq DNA polymerase, $2.5 \mathrm{mM} \mathrm{MgCl} 2,0.25 \mathrm{mM}$ dNTP's and $0.01 \mathrm{mM}$ of primers. The primary PCR product was diluted 1:10 times, before performing the nested reaction. All the primer sequence and PCR conditions are described in Table 1. For pfmdr-1 N86Y mutation, the nested PCR product was subjected to restriction digestion at $37^{\circ} \mathrm{C}$ with $5 \mathrm{U}$ of AflIII (MBI, Fermentas) endonuclease for $6 \mathrm{~h}$.

\section{Sequence analysis}

Final $p f c r t$ PCR product was purified with a column based gel extraction kit (MDI, India), and then was subjected to automated sequencing. The sequences obtained were aligned using MegAlign module of Lasergene Version 5 (DNASTAR, Inc., USA).

\section{Statistical analysis}

A $\chi^{2}$ test or Fisher's exact test (GraphPad Software, Inc) was used to compare the frequency of $p f c r t$ haplotypes between groups of high and low P. falciparum endemicity.

\section{Results}

The data in this study has been analysed in two ways: (i) regional distribution of mutations (sites 1-11) and (ii) mutation analysis in relation to in vivo CQ efficacy clinical trial (sites 1-8).

\section{Regional distribution of pfcrt and pfmdr-1 mutations}

After the $p f c r t$ gene was sequenced for all 287 isolates from 11 different study sites, the mutations were assembled into a single haplotype by concatenating the amino acids located in positions $72-76$ and position 220 . The distribution of pfcrt haplotypes is presented in Table 2. The mutant SVMNT-S haplotype was the most prevalent haplotype within all sites, comprising 192 (66.89\%) of all the isolates observed in this study. Not surprisingly, there was less diversity in the low transmission regions, compared to the high transmission regions; however, this limited diversity was dominated by the mutant SVMNT-S haplotype (125 of 127 isolates or $98.42 \%$ ). There were three major haplotypes found within regions of high transmission across India: (i) the mutant haplotype SVMNT-S comprises $67(41.87 \%)$ of the total; (ii) the mutant haplotype CVIET-S comprises 56 (35.00\%) of the total; and (iii) the wild type haplotype CVMNK-A comprises 34 (21.25\%) of the total. Compared with the low transmission regions, 
Table 1 Description of primer sequences and respective PCR amplification conditions

\begin{tabular}{|c|c|c|}
\hline Amplified region & Primer sequence \# & Amplification condition \\
\hline $\begin{array}{l}\text { pfort gene (codons } \\
32-119)\end{array}$ & $\begin{array}{l}\text { Primary 20: PFCRT 1F 5'CCGTTAATAATAAATACAGGC-3' PFCRT 1R } \\
\text { 5'CTITAAAAATGGAAGGGTGT 3' Nested 16: PFK76T } \\
\text { 5'-5'GGCTCACGTTAGGTGGA3' PRK76T } \\
\text { 5'TGAATTCCCTITTATTCCAAA 3' }\end{array}$ & $\begin{array}{l}94^{\circ} \mathrm{C} 5 \min ; 94^{\circ} \mathrm{C} 30 \mathrm{sec}, 56^{\circ} \mathrm{C} 1 \mathrm{~min}, 60^{\circ} \mathrm{C} 90 \mathrm{sec}(40 \mathrm{X}), 60^{\circ} \mathrm{C} \\
3 \mathrm{~min} .94^{\circ} \mathrm{C} 5 \mathrm{~min} ; 94^{\circ} \mathrm{C} 30 \mathrm{sec}, 52^{\circ} \mathrm{C} 45 \mathrm{sec}, 72^{\circ} \mathrm{C} 45 \mathrm{sec} \\
(35 \mathrm{X}), 72^{\circ} \mathrm{C} 5 \mathrm{~min} .\end{array}$ \\
\hline $\begin{array}{l}\text { pfcrt gene (codons } \\
\text { 181-222) }\end{array}$ & $\begin{array}{l}\text { Primary 20: PFCRT 1F 5'CCGTTAATAATAAATACAGGC-3' PFCRT 1R } \\
\text { 5'CTITAAAAATGGAAGGGTGT 3' Nested 48: PFA220S } \\
\text { 5'CTATACAATTATCTCGGAGCAG3' PRA220S } \\
\text { 5'ATAATAAAAACAAAGTTAAGTGT 3' }\end{array}$ & $\begin{array}{l}\text { Same as for above primary } 94^{\circ} \mathrm{C} 5 \mathrm{~min} ; 94^{\circ} \mathrm{C} 30 \mathrm{sec}, 51^{\circ} \mathrm{C} \\
45 \mathrm{sec}, 72^{\circ} \mathrm{C} 45 \mathrm{sec}(35 \mathrm{X}), 72^{\circ} \mathrm{C} 5 \mathrm{~min} .\end{array}$ \\
\hline $\begin{array}{l}\text { pfmdr-1 gene } \\
\text { (N86Y) }\end{array}$ & $\begin{array}{l}\text { Primary 16: MDR1F 5'ATGGGTAAAGAGCAGAAAGA3' MDR1R } \\
\text { 5'AACGCAAGTAATACATAAAGTCA3' Nested 47: MDR1FN } \\
\text { 5'AGATGGTAACCTCAGTATCA3' MDR1RN } \\
\text { 5'TTACATCCATACAATAACTTG3' }\end{array}$ & $\begin{array}{l}94^{\circ} \mathrm{C} 5 \mathrm{~min} ; 94^{\circ} \mathrm{C} 30 \mathrm{sec}, 54^{\circ} \mathrm{C} 45 \mathrm{sec}, 72^{\circ} \mathrm{C} 45 \mathrm{sec} \mathrm{sec}(35 \mathrm{X}), \\
72^{\circ} \mathrm{C} 5 \mathrm{~min} .94^{\circ} \mathrm{C} 5 \mathrm{~min} ; 94^{\circ} \mathrm{C} 30 \mathrm{sec}, 49^{\circ} \mathrm{C} 45 \mathrm{sec}, 72^{\circ} \mathrm{C} 45 \mathrm{sec} \\
(35 \mathrm{X}), 72^{\circ} \mathrm{C} 5 \mathrm{~min} .\end{array}$ \\
\hline
\end{tabular}

\# Primer sequences were adapted from Dorsey et al. [20]; Vathsala et al. [16]; Jelinek et al. [28] and Lim et al. [29]

both the CVIET-S mutant and the wild type CVMNK-A haplotype occurred at significantly higher frequencies in the high transmission regions $\left(\mathrm{P}<0.001, \chi^{2}\right)$.

For the 286 isolates tested for N86Y mutation throughout India, the wild type N86 was observed in 211 (73.77\%) isolates. Regional distribution of $p f m d r-1$ mutation is presented in Table 2. The wild type N86 was significantly more prevalent in the low transmission regions $(\mathrm{n}=120,94.48 \%)$, whereas in high transmission regions, the wild type (N86) and the mutant (N86Y) were found in similar proportions, 91 (57.23\%) and 68 $(42.76 \%)$ respectively $\left(\mathrm{P}<0.0001, \chi^{2}\right)$. The N86Y was predominantly observed in Assam (76.00\%) and Orissa (51.85\%) isolates, whereas wild type N86 was observed more in isolates from West Bengal (75.00\%), Chhattisgarh $(81.25 \%)$ and Maharastra (100\%).

\section{Distribution of haplotypes}

The combination of $p f c r t$ haplotypes and Pfmdr-1 mutations revealed nine haplotypes distributed at variying rates within different field sites (Table 2). The haplotype SVMNTS-N occurred in 154 (53.84\%) isolates and was detected in all sites. Its significant occurrence in low P. falciparum transmission areas 118 (92.91\%) isolates is understandable, as a higher number of SVMNT-S and N86 was previously observed in these areas. The other mutant haplotype, SVMNTS-Y was observed in 5.51\% isolates from low P. falciparum transmission areas, while CVIETS-N and CVMNKA-N each were observed only one time. In contrast, there was considerable variation observed in the haplotypes from isolates collected in high P. falciparum transmission areas i.e. $32(20.12 \%)$ wild type CVMNKA-N and various mutant types SVMNTS-N $(\mathrm{n}=36,22.64 \%)$, CVIETS-Y $(\mathrm{n}=34,21.38 \%)$, SVMNTS$\mathrm{Y}(\mathrm{n}=30,18.86 \%)$, CVIETS-N $(\mathrm{n}=22,13.83 \%)$, CVMNKA-Y $(\mathrm{n}=2,1.25 \%)$ and one isolate $(0.62 \%)$ of the following haplotypes SVMNTA-N, CVMDTS-Y, CVMNKS-N.

\section{Distribution of pfcrt and pfmdr-1 mutations in relation to in vivo $\mathrm{CQ}$ efficacy}

A total of 240/287 isolates collected from the CQ therapeutic efficacy study [25-27] were sequenced for analysis of pfcrt gene. The mutant K76T was observed irrespective of treatment outcome. Of the 106 isolates identified as ACPR (i.e. CQ sensitive isolates), 87 (82.07\%) were found to be mutant K76T, while only 19 (17.92\%) contained the wild pfcrt haplotype CVMNKA. The mutant K76T was observed in the remaining 134 cases classified as treatment failures (i.e. ETF and LTF). Though the wild type was observed infrequently across India, it was almost exclusively detected in high transmission regions $(\mathrm{n}=$ $18,94.73 \%)$ compared to low transmission region $(\mathrm{n}=$ 1,5.26\%). The mutant pfcrt haplotype SVMNT-S was prevalent in all treatment outcomes, i.e. observed in 71 (66.98\%) ACPR, 15 (60.00\%) ETF, and 76 (69.72\%) LTF isolates. On the other hand, occurrence of mutant haplotype CVIET-S was almost entirely limited to high P. falciparum transmission regions and was distributed in all the clinical outcomes, 15 (14.15\%) ACPR, 10 (40.00\%) ETF, and $32(29.35 \%)$ LTF isolates. Only a single isolate from Goa, a low transmission region was identified by the CVIET-S haplotype. Instances of rare haplotypes were also observed; CVMDT-S haplotype was observed in one of the LTF isolate from Jharkhand and SVMNT-A haplotype was observed in one of the ACPR isolates from Orissa. The distribution of $p f c r t$ haplotypes in various clinical outcomes is presented in Table 3.

In total, 239 isolates underwent successful PCR amplification and endonuclease digestion for $p f m d r-1 \mathrm{~N} 86 \mathrm{Y}$ mutation. The distribution of the $p f m d r-1$ mutation N86Y in the different clinical outcomes is shown in Table 3. In brief, both the wild type and the mutant alleles were detected in each of the three different clinical outcomes; no significant association was found between wildtype and mutant alleles and the treatment outcome. The wild type N86 allele was observed in 167 (69.87\%) of 
Table 2 Distribution of pfcrt haplotypes, pfmdr-1 N86Y mutation and (pfcrt-pfmdr-1) 2 loci mutation i.e. combined genotype

\begin{tabular}{|c|c|c|c|c|c|c|c|c|c|c|c|c|c|}
\hline \multirow[b]{2}{*}{ pfcrt haplotype ${ }^{a}$} & \multirow[b]{2}{*}{ Assam } & \multicolumn{6}{|c|}{ no. of isolates (\%) in high P.falciparum prevalent areas } & \multicolumn{6}{|c|}{ no. of isolates (\%) in low P.falciparum prevalent areas } \\
\hline & & Orissa & Jharkhand & West Bengal & Chhattisgarh & Maharastra & total & Gujarat & Goa & Tamil Nadu & Rajasthan & Uttar Pradesh & total \\
\hline CVMNK-A & 0 & $11(20.37)$ & $7(20.58)$ & 0 & $11(68.75)$ & $5(35.72)$ & $34(21.25)$ & 0 & 0 & 0 & 1(3.85) & 0 & $1(0.78)$ \\
\hline CVIET-S & 15(57.69) & 17(31.48) & 20(58.82) & $4(25)$ & 0 & 0 & $56(35)$ & 0 & 1(3.85) & 0 & 0 & 0 & $1(0.78)$ \\
\hline SVMNT-S & $11(42.30)$ & 25(46.29) & $6(17.64)$ & $12(75)$ & $4(25)$ & $9(64.28)$ & $67(41.87)$ & $33(100)$ & 25(96.15) & $25(100)$ & 25(96.25) & $17(100)$ & 125(98.42) \\
\hline CVMDT-S & 0 & 0 & $1(2.94)$ & 0 & 0 & 0 & $1(0.62)$ & 0 & 0 & 0 & 0 & 0 & 0 \\
\hline CVMNK- $\underline{S}$ & 0 & 0 & 0 & 0 & $1(6.25)$ & 0 & $1(0.62)$ & 0 & 0 & 0 & 0 & 0 & 0 \\
\hline \multicolumn{14}{|l|}{ pfmdr mutation ${ }^{b}$} \\
\hline N86 wt & $6(24)$ & $28(51.85)$ & $18(52.94)$ & $12(75)$ & $13(81.25)$ & $14(100)$ & $91(57.23)$ & $32(96.96)$ & $26(100)$ & $24(96)$ & 21(80.76) & $17(100)$ & $120(94.48)$ \\
\hline N86Y $m t$ & $19(76)$ & $26(48.14)$ & $16(47.05)$ & $4(25)$ & $3(18.75)$ & 0 & $68(42.76)$ & $1(3.03)$ & & $1(4)$ & $5(19.23)$ & & $7(5.51)$ \\
\hline \multicolumn{14}{|l|}{ Combined genotype $e^{a}$} \\
\hline CVIETS -N & $3(12)$ & $8(14.81)$ & $11(32.35)$ & 0 & 0 & 0 & $22(13.83)$ & 0 & $1(3.85)$ & 0 & 0 & 0 & $1(0.78)$ \\
\hline CVIETS -Y & $12(48)$ & $9(16.66)$ & $9(26.47)$ & $4(25)$ & 0 & 0 & $34(21.38)$ & 0 & 0 & 0 & 0 & 0 & 0 \\
\hline SVMNTA -N & 0 & $1(1.8)$ & 0 & 0 & 0 & 0 & $1(0.62)$ & 0 & 0 & 0 & 0 & 0 & 0 \\
\hline SVMNTS -N & $3(12)$ & $10(18.51)$ & $1(2.9)$ & $12(75)$ & $1(6.25)$ & $9(64.28)$ & $36(22.64)$ & $32(96.96)$ & 25(96.15) & $24(96)$ & $20(76.92)$ & $17(100)$ & 118(92.91) \\
\hline SVMNTS-Y & $7(28)$ & $15(27.77)$ & $5(14.7)$ & 0 & $3(18.75)$ & 0 & $30(18.86)$ & $1(3.03)$ & 0 & $1(4)$ & $5(19.23)$ & 0 & $7(5.51)$ \\
\hline CVMNKA-N & 0 & $9(16.66)$ & $7(20.58)$ & 0 & $11(68.75)$ & $5(35.71)$ & $32(20.12)$ & 0 & 0 & 0 & $1(3.85)$ & 0 & $1(0.78)$ \\
\hline CVMNKA-Y & 0 & $2(3.7)$ & 0 & 0 & 0 & 0 & $2(1.25)$ & 0 & 0 & 0 & 0 & 0 & 0 \\
\hline CVMDTS $\underline{-\underline{Y}}$ & 0 & 0 & $1(2.9)$ & 0 & 0 & 0 & $1(0.62)$ & 0 & 0 & 0 & 0 & 0 & 0 \\
\hline CVMNKS $-\bar{N}$ & 0 & 0 & 0 & 0 & $1(6.25)$ & 0 & $1(0.62)$ & 0 & 0 & 0 & 0 & 0 & 0 \\
\hline
\end{tabular}

${ }^{\mathrm{a}}$ Mutated amino acid is underlined, ${ }^{\mathrm{b}}$ wt Wild type, $m t$ Mutant type 
Table 3 The distribution of mutations in different clinical responses

\begin{tabular}{|c|c|c|c|c|c|c|c|c|c|c|}
\hline CQ RESPONSE & & ASSAM $^{\mathrm{a}}$ & ORISSA & JHARKHAND & W.BENGAL & GUJARAT & GOA & TAMIL NADU & RAJASTHAN & TOTAL \\
\hline \multirow[t]{15}{*}{ ACPR } & pfcrt haplotype $^{b}$ & & & & & & & & & \\
\hline & CVMNK-A & 0 & $11(45.83)$ & $7(41.17)$ & 0 & 0 & 0 & 0 & $1(3.85)$ & 19(17.92) \\
\hline & CVIET-S & $5(41.66)$ & $3(12.50)$ & $6(35.29)$ & $1(14.28)$ & 0 & 0 & 0 & 0 & $15(14.15)$ \\
\hline & SVMNT-A & 0 & $1(4.16)$ & 0 & 0 & 0 & 0 & 0 & 0 & $1(0.94)$ \\
\hline & $\begin{array}{c}\underline{S V M N T-S}-\underline{S} \\
\text { pfm }^{2} r \text { mutation } \\
\end{array}$ & $7(58.33)$ & $9(37.50)$ & $4(23.52)$ & $6(85.71)$ & $6(100)$ & $8(100)$ & $6(100)$ & 25(96.25) & $71(66.98)$ \\
\hline & N86 wt & $1(9.09)$ & $18(75.00)$ & $13(76.47)$ & $6(85.71)$ & $6(100)$ & $8(100)$ & $6(100)$ & $21(80.76)$ & $79(75.23)$ \\
\hline & N86Y mt & 10(90.90) & $6(25.00)$ & $4(23.52)$ & $1(14.28)$ & 0 & 0 & 0 & $5(19.23)$ & $26(24.76)$ \\
\hline & Combined genotype $^{b}$ & & & & & & & & & \\
\hline & CVMNKA N & 0 & $9(37.50)$ & 7(41.17) & 0 & 0 & 0 & 0 & $1(3.85)$ & $17(16.19)$ \\
\hline & CVMNKA $\underline{Y}$ & 0 & $2(8.33)$ & 0 & 0 & 0 & 0 & 0 & 0 & $2(1.90)$ \\
\hline & $\underline{\text { SVMNTS }} \mathrm{N}$ & 0 & $6(25.00)$ & $1(5.88)$ & $6(85.71)$ & $6(100)$ & $8(100)$ & $6(100)$ & 20(76.92) & $53(50.47)$ \\
\hline & SVMNTSY & $6(54.54)$ & $3(12.50)$ & $3(17.64)$ & 0 & 0 & 0 & 0 & $5(19.23)$ & $17(16.19)$ \\
\hline & SVMNTA N & 0 & $1(4.16)$ & 0 & 0 & 0 & 0 & 0 & 0 & $1(0.95)$ \\
\hline & CVIETS N & $1(9.09)$ & $2(8.33)$ & $5(29.41)$ & 0 & 0 & 0 & 0 & 0 & $8(7.61)$ \\
\hline & CVIETSY & 4(36.36) & $1(4.16)$ & $1(5.88)$ & $1(14.28)$ & 0 & 0 & 0 & 0 & $7(6.66)$ \\
\hline \multirow[t]{10}{*}{ ETF } & pfcrt haplotype & & & & & & & & & \\
\hline & CVIET-S & $2(40)$ & $4(66.66)$ & $2(100)$ & $1(50)$ & 0 & $1(11.11)$ & 0 & 0 & $10(40.00)$ \\
\hline & $\begin{array}{c}\text { SVMNT-S } \\
\text { pfmdr mutation }\end{array}$ & $3(60)$ & 2(33.33) & 0 & $1(50)$ & $1(100)$ & $8(88.88)$ & 0 & 0 & $15(60.00)$ \\
\hline & N86 wt & $4(80)$ & 2(33.33) & $1(50)$ & $1(50)$ & $1(100)$ & $9(100)$ & 0 & 0 & 18(72.00) \\
\hline & $\mathrm{N} 86 \mathrm{Y} \mathrm{mt}$ & $1(20)$ & $4(66.66)$ & $1(50)$ & $1(50)$ & 0 & 0 & 0 & 0 & $7(28.00)$ \\
\hline & combined genotype & & & & & & & & & \\
\hline & $\underline{\text { SVMNTS }} \mathrm{N}$ & $2(40)$ & $1(16.66)$ & 0 & $1(50)$ & $1(100)$ & $8(88.88)$ & 0 & 0 & $13(52.00)$ \\
\hline & $\underline{\text { SVMNTSY }}$ & $1(20)$ & $1(16.66)$ & 0 & 0 & 0 & 0 & 0 & 0 & $2(8.00)$ \\
\hline & CVIETS N & $2(40)$ & $1(16.66)$ & $1(50)$ & 0 & 0 & $1(11.11)$ & 0 & 0 & $5(20.00)$ \\
\hline & CVIETSY & 0 & $3(50.00)$ & $1(50)$ & $1(50)$ & 0 & 0 & 0 & 0 & $5(20.00)$ \\
\hline \multirow[t]{13}{*}{ LTF } & pfcrt haplotype & & & & & & & & & \\
\hline & CVIET-S & $8(88.88)$ & 10(41.66) & $12(80)$ & $2(28.57)$ & 0 & 0 & 0 & 0 & $32(29.35)$ \\
\hline & $\underline{\text { SVMNTI-S }}$ & $1(11.11)$ & 14(58.33) & $2(13.33)$ & $5(71.42)$ & $26(100)$ & $9(100)$ & $19(100)$ & 0 & $76(69.72)$ \\
\hline & CVMDT-S & 0 & 0 & $1(6.66)$ & 0 & 0 & 0 & 0 & 0 & $1(0.91)$ \\
\hline & pfmdr mutation & & & & & & & & & \\
\hline & N86 wt & $1(11.11)$ & 8(33.33) & $4(26.66)$ & $5(71.42)$ & 25(96.15) & $9(100)$ & 18(94.73) & 0 & $70(64.22)$ \\
\hline & N86Y mt & $8(88.88)$ & 16(66.66) & $11(73.33)$ & $2(28.57)$ & 1(3.84) & 0 & $1(5.26)$ & 0 & $39(35.77)$ \\
\hline & combined genotype & & & & & & & & & \\
\hline & $\underline{\text { SVMNTS N }}$ & $1(11.11)$ & $3(12.50)$ & 0 & $5(71.42)$ & 25(96.15) & $9(100)$ & 18(94.73) & 0 & $61(55.96)$ \\
\hline & SVMNTSY & 0 & $11(45.83)$ & $2(13.33)$ & 0 & $1(3.84)$ & 0 & $1(5.26)$ & 0 & 15(13.76) \\
\hline & CVIETS N & 0 & $5(20.83)$ & $5(33.33)$ & 0 & 0 & 0 & 0 & 0 & $10(9.17)$ \\
\hline & CVIETSY & $8(88.88)$ & $5(20.83)$ & $7(46.66)$ & $2(28.57)$ & 0 & 0 & 0 & 0 & $22(20.18)$ \\
\hline & CVMDTSY & 0 & 0 & 1(6.66) & 0 & 0 & 0 & 0 & 0 & $1(0.91)$ \\
\hline
\end{tabular}


the 239 isolates and distributed accordingly; 79 (75.23\%) ACPR, 18 (72.00\%) ETF, and 70 (64.22\%) as LTF. Similarly mutant N86Y allele was found in 26 (24.76\%) of isolates classified as ACPR, 7(28.00\%) as ETF and 39 (35.77\%) as LTF. The combination of pfcrt haplotypes and Pfmdr-1 mutations revealed again, that SVMNTS-N prevail in all the category of clinical outcome also; 53 (50.47\%) isolates in ACPR, 13 (52.00\%) isolates in ETF, 61 (55.96\%) isolates in LTF.

\section{Discussion}

In this study, the distribution of pfcrt haplotypes and the pfmdr-1 mutation (N86Y) has been described across 11 sites in India and evaluated for a correlation between the prevalence of mutations and the clinical outcome of $\mathrm{CQ}$ treatment. The distribution of pfcrt haplotypes in association with the clinical outcome of treatment supports that the K76T mutation is the most predictive marker of CQR in the field $[3,4]$. The wild type CVMNK-A haplotype was found to be exclusively restricted to the ACPR outcome group ( $\mathrm{P}<0.001$, Fisher's exact test). However, the wild type CVMNK-A haplotype was not the predominant haplotype in the ACPR outcome group; in fact, $82.07 \%$ of the isolates identified as ACPR carried a mutant haplotype. From this data, it is proposed that the typing of molecular markers for CQ resistance may infer an intrinsic characteristic of the parasite, but may not necessarily be sufficient to predict treatment outcome. Treatment outcome may depend on other factors, such as host-parasite or host-drug interaction [30]. Exposure-related host immunity may play an essential role in naturally clearing the parasite infection, irrespective of their response to any drug. Some studies have shown that host immunity is also associated with clearance of resistant genotypes [20,31].

Additionally, the mutant haplotype SVMNT-S (characteristic of South American or PNG CQR isolates) was observed in all sites across India, regardless of the clinical outcome. Observation made in this study support earlier reports regarding the prevalence of SVMNT-S haplotype among the CQR isolates in India [16-18]. Perhaps the most striking observation observation in the study is that the SVMNT-S haplotype is endemic across all the sites of low P. falciparum malaria transmission, while in high transmission regions there are multiple mutant $p f c r t$ haplotypes observed. These different haplotype combinations observed in regions of high transmission might be indicative of random mating patterns among parasites within these regions, which could be influenced by the local rate of malaria transmission. The role of transmission in the evolution and spread of drug resistance remains a matter of debate, as it has been hypothesized by some that low transmission may decrease circulating drug resistance, while others hypothesize that low transmission may increase drug resistance $[32,33]$. These studies signify the effect of transmission on altering the spread of drug resistance. In this study, the distribution of mutations hints that the spread of CQR might be under the influence of the transmission intensity and the distribution of antimalarial drugs. Though complexity of infection (minimum number of clones within an infection) was not characterized in this study, it is common to observe a higher proportion of multiclonal infections in regions of high transmission, compared to regions of low transmission [34-37]. The ubiquitous nature of mutant SVMNT-S pfcrt haplotype in the low transmission regions in this study may be a direct consequence of higher inbreeding potential of resistant parasites due to low frequencies of complex and multiclonal infections. An inbreeding population, consisting mostly of resistant genotypes could spread parasite drug resistance expeditiously [32,38]. This expansion of mutant SVMNT-S is likely to be enhanced by extensive exposure of CQ in these $P$. vivax predominated areas, as chloroquine is the first-line drug for vivax malaria in India. A similar expansions hasbeen observed for the $p f m d r-1$ wild type N86 in these P. vivax prevalent areas. Again inbreeding might be the cause for this expansion in low transmission regions.

The significant presence of wild type CVMNK-A in high P. falciparum prevalent areas (Orissa, Jharkhand, Chhattisgarh) supports earlier reports on acquisition of immunity in high endemic areas, which creates a natural ecological refuge for drug sensitive parasites [31,39]. This could possibly explain the occurrence of the wild type haplotype in high $P$. falciparum prevalent areas. Further, appearance of the mutant haplotype CVIET-S(characteristic of Southeast Asian CQR parasite) is expected to be observed within eastern and northeastern parts of the country, because this region shares international borders with Bangladesh, Nepal, Bhutan, Myanmar and China and harbour migrant populations. The CVIET-S haplotype might be indicative of high drug pressure in regions of high transmission, as earlier observations have shown that the CVIET-S haplotype have higher $\mathrm{IC}_{50}$ for $\mathrm{CQ}[17,40]$. Similarly, the prevalence of $p f m d r-1$ mutant N86Y found in these areas may be involved in modulating the CQ response in Indian isolates. Isolates with the two loci mutation (pfcrt-pfmdr-1) were limited to high $P$. falciparum transmission regions, where N86Y appeared with both the pfcrt mutant haplotype SVMNT-S and CVIET-S. These two mutant haplotypes were observed in high numbers at Assam, Orissa, and Jharkhand, whereas Chhattisgarh shows a higher frequency of the wild type for both loci. This study has not evaluated $\mathrm{IC}_{50}$ values for particular $p f c r t$ haplotypes, but the observed prevalence of the mutant SVMNT-S, even in the high transmission regions may be an indication of increased transmission potential of these resistant parasites [40]. The use of amodiaquine as monotherapy or in combination has been associated with the prevalence of 
SVMNT haplotype in chloroquine resistant areas $[41,42]$. In India, amodiaquine was used as presumptive antimalarial drug for CQR parasite in 1980's in these high transmission regions [43-45] and may be a possible explanation for the introduction and spread of SVMNT-S haplotype. On the other hand, a recent investigation from central India, using multilocus microsatellites, compared the evolutionary proximity of Indian SVMNT-S haplotype with other parts of the world and reveals its close relation to the SVMNT genotype found in PNG [19]. So, overall the spread of SVMNT is intriguing and require further investigation about its origin and spread in India.

The observed prevalence of the wild type $p f m d r-1$ N86 allele could be a cause for concern, because a recent study reported that the selection of this allele is associated with resistance to one of the artemisinin-based combination therapy (ACT-Coartem ${ }^{\circledR}$ ) desseminated in East Africa [46]. This allele has also been associated with a decreased sensitivity to lumefantrine in vitro $[47,48]$. Furthermore, the significant prevalence $(\mathrm{P}<0.001)$ of wild type N86 in low P. falciparum prevalent areas, seems to be fixed and may result in an easy escape for parasites exposed to this drug combination. Ultimately, this fixation could lead to the rapid spread of resistant parasites. However, a recent investigation of therapeutic efficacy of Coartem ${ }^{\circledR}$ in the high $P$. falciparum transmission regions marks successful outcome without any selection of N86 [49].

\section{Conclusions}

This studyobserved a striking pattern in fixation of mutant SVMNT pfcrt haplotype at low P. falciparum prevalent areas, which raise concerns about faster spread of anti-malarial resistance in these areas. The absence of wild type $p f c r t$ haplotype in most part of the country may lead to a situation where no reversal of wild type would happen even in the absence of CQ pressure. This study leads towards understanding the role of malaria transmission intensity in spread of anti-malarial resistant parasite in India, and it will be useful in designing antimalarial treatment policy.

\section{Acknowledgements \\ PKM is grateful to the Council of Scientific and Industrial Research, India, for Senior Research fellowship. This study was partly supported by grant D43TW007884 "Promotion of Plasmodium Research and Training in India" from the National Institutes of Health/Fogarty International Center. The content is solely the responsibility of the authors and does not necessarily represent the official views of the Fogarty International Center or the National Institutes of Health. We sincerely thank all the staff members of NIMR, Delhi and the respective field units, for their help, cooperation and support during the study. Authors express their deep gratitude to Dr. Hema Joshi, who passed away recently and she had contributed significantly to the present study.}

\section{Author details}

${ }^{1}$ National Institute of Malaria Research, Dwarka Sector-8, Delhi 110077, India. ${ }^{2}$ National Institute of Malaria Research (Field Unit), Rourkela 769002, India.
${ }^{3}$ National Institute of Malaria Research (Field Unit), Chennai 600037, India. ${ }^{4}$ National Institute of Malaria Research (Field Unit), Raipur 492015, India. ${ }^{5}$ National Institute of Malaria Research (Field Unit), Nadiad 387001, India. ${ }^{6}$ Department of Biology, Center for Genomics \& System Biology, New York University, New York, USA. ${ }^{7}$ Department of Zoology, University of Delhi, Delhi 110007, India. ${ }^{8}$ W.H.O SEARO, Delhi, India.

\section{Authors' contributions}

PKM carried out the experiment design, experimental work, data analysis, and manuscript writing. NV, APD, HJ conceived and coordinated the study. $N V$, SKS, AE, RMB, HCS, APD supervised all the field work. PLS has contributed in data analysis and manuscript writing. VKB supervised overall work and contributed in data analysis and manuscript writing. All authors read and approved the final manuscript.

\section{Competing interests}

The authors declare that they have no competing interests.

Received: 2 August 2011 Accepted: 11 January 2012

Published: 11 January 2012

\section{References}

1. Wongsrichanalai C, Pickard AL, Wernsdorfer WH, Meshnick SR Epidemiology of drug-resistant malaria. Lancet Infect Dis 2002, 2:209-218.

2. Fidock DA, Nomura T, Talley AK, Cooper RA, Dzekunov SM, Ferdig MT, Ursos LM, Sidhu AB, Naudé B, Deitsch KW, Su XZ, Wootton JC, Roepe PD, Wellems TE: Mutation in the $P$. falciparu digestive vacuole transmembrane protein PfCRT and evidence for their role in chloroquine resistance. Mol Cell 2000, 6:861-871.

3. Djimdé A, Doumbo OK, Cortese JF, Kayentao K, Doumbo S, Diourté Y, Dicko A, Su XZ, Nomura T, Fidock DA, Wellems TE, Plowe CV, Coulibaly D: A molecular marker for chloroquine resistant falciparum malaria. NEJM 2001, 334:257-263

4. Djimdé A, Doumbo OK, Steketee RW, Plowe CV: Application of a molecular marker for surveillance of chloroquine-resistant falciparum malaria. Lancet 2001, 358:890-891.

5. Cooper RA, Hartwig CL, Ferdig MT: Pfcrt is more than the Plasmodium falciparu chloroquine resistance gene: a functional and evolutionary perspective. Acta Trop 2005, 94:170-180.

6. Wootton JC, Feng X, Ferdig MT, Cooper RA, Mu J, Baruch DI, Magill AJ, Su XZ: Genetic diversity and chloroquine selective sweeps in Plasmodium falciparu. Nature 2002, 418:320-323.

7. Mehlotra RK, Fujioka H, Roepe PD, Janneh O, Ursos LM, Jacobs-Lorena V, McNamara DT, Bockarie MJ, Kazura JW, Kyle DE, Fidock DA, Zimmerman PA: Evolution of a unique Plasmodium falciparu chloroquine-resistance phenotype in association with pfcrt polymorphism in Papua New Guinea and South America. Proc Natl Acad Sci USA 2001, 98:12689-12694

8. Chen N, Wilson DW, Pasay C, Bell D, Martin LB, Kyle D, Cheng Q: Origin and dissemination of chloroquine-resistant Plasmodium falciparu with mutant pfcrt alleles in the Philippines. Antimicrob Agents Chemother 2005, 49:2102-2105

9. Cortese JF, Caraballo A, Contreras CE, Plowe CV: Origin and dissemination of Plasmodium falciparu drug-resistance mutations in South America. $J$ Infect Dis 2002, 186:999-1006.

10. Mehlotra RK, Mattera G, Bhatia K, Reeder JC, Stoneking M, Zimmerman PA: Insight into the early spread of chloroquine-resistant Plasmodium falciparu infections in Papua New Guinea. J Infect Dis 2005, 192:2174-2179.

11. Vieira PP, Ferreira MU, Das G, Alecrim M, Alecrim WD, Da Silva LH, Sihuincha MM, Joy DA, Mu J, Su XZ, Zalis MG: pfcr polymorphism and the spread of chloroquine resistance in Plasmodium falciparu populations across the Amazon basin. J Infect Dis 2004, 190:417-424.

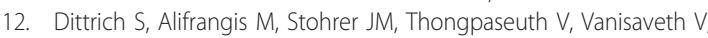
Phetsouvanh R, Phompida S, Khalil IF, Jelinek T: Falciparum malaria in the north of Laos: the occurrence and implications of the Plasmodium falciparu chloroquine resistance transporter (pfcrt) gene haplotype SVMNT. Trop Med Int Health 2005, 10:1267-1270.

13. Ariey F, Fandeur $T$, Durand $R$, Randrianarivelojosia M, Jambou R, Legrand $E$, Ekala MT, Bouchier C, Cojean S, Duchemin JB, Robert V, Le Bras J, Mercereau-Puijalon O: Invasion of Africa by a single pfcr allele of South East Asian type. Malar J 2006, 5:34 
14. Sehgal PN, Sharma MID, Gogai S: Resistance to chloroquine in falciparum malaria in Assam State, India. J Comm Dis 1973, 5:175-180.

15. Sharma VP: Battling the malaria iceberg with chloroquine in India. Malar J 2007, 6:105.

16. Vathsala PG, Pramanik A, Dhanasekkaran S, Devi CU, Pillai CR, Subbarao SK, Ghosh SK, Tiwari SN, Sathyanarayan TS, Deshpande PR, Mishra GC, Ranjit MR, Dash AP, Rangarajan PN, Padmanaban G: Widespread occurrence of the Plasmodium falciparu chloroquine resistance transporter (PfCRT) gene haplotype SVMNT in $P$. falciparu malaria in India. Am J Trop Med Hyg 2004, 70:256-259.

17. Mittra P, Vinayak S, Chandawat H, Das MK, Singh N, Biswas S, Dev V, Kumar A, Ansari MA, Sharma YD: Progressive increase in point mutations associated with chloroquine resistance in Plasmodium falciparu isolates from India. J Infect Dis 2006, 193:1304-1312.

18. Keen J, Farcas GA, Zhong K, Dunne MW, Kain KC: Real-Time PCR assay for rapid detection and analysis of PfCRT haplotype of chloroquine-resistant Plasmodium falciparu isolates from India. J Clin Microbiol 2007, 45:2889-2893.

19. Mixson-Hayden T, Jain V, McCollum AM, Poe A, Nagpal AC, Dash AP, Stiles JK, Udhayakumar V, Singh N: Evidence of selective sweeps in genes conferring resistance to chloroquine and pyrimethamine in Plasmodium falciparum isolates in India. Antimicrob Agents Chemother 2010, 54:997-1006.

20. Dorsey G, Kamya MR, Singh A, Rosenthal P: Polymorphisms in the Plasmodium falciparum pfcrt and pfmdr-1 genes and clinical response to chloroquine in Kampala, Uganda. J Infect Dis 2001, 183:1417-1420.

21. Foote SJ, Kyle DE, Martin RK, Oduola AM, Forsyth K, Kemp DJ, Cowman AF: Several alleles of the multi drug resistance gene are closely linked to chloroquine resistance in Plasmodium falciparu. Nature 1990, 345:255-258.

22. Mu J, Ferdig MT, Feng X, Joy DA, Duan J, Furuya T, Subramanian G, Aravind L, Cooper RA, Wootton JC, Xiong M, Su XZ: Multiple transporters associated with malaria parasite responses to chloroquine and quinine. Mol Microbiol 2003, 49:977-989

23. Wellems TE, Panton LJ, Gluzman IY, do Rosario VE, Gwadz RW, Walke Jonah A, Krogstad DJ: Chloroquine resistance not linked to mdr-like genes in Plasmodium falciparu cross. Nature 1990, 345:253-255.

24. Singh N, Nagpal AC, Saxena A, Singh MP: Changing scenario of malaria in central India, the replacement of Plasmodium viva by Plasmodium falciparu (1986-2000). Trop Med Int Health 2004, 9:364-371.

25. Eapen A, Ravindran KJ, Josh H, Dhiman RC, Balavinayagam S, Mallick PK, Kumar R, Rajendran C, Selvakumar AD, Dash AP: Detection of in-vivo chloroquine resistance in Plasmodium falciparu from Rameswaram Island, a pilgrim centre in southern India. Ann Trop Med Parasitol 2007 101:305-313

26. Srivastava HC, Yadav RS, Joshi $H$, Valecha N, Mallick PK, Prajapati SK, Dash AP: Therapeutic responses of Plasmodium viva and $P$. falciparu to chloroquine, in an area of western India where $P$. viva predominates. Ann Trop Med Parasitol 2008, 102:471-480.

27. Valecha N, Joshi H, Mallick PK, Sharma SK, Kumar A, Tyagi PK, Shahi B, Das MK, Nagpal BN, Dash AP: Low efficacy of chloroquine: time to switchover to artemisinin-based combination therapy for falciparum malaria in India. Acta Trop 2009, 111:21-28.

28. Jelinek T, Aida AO, Peyerl-Hoffmann G, Jordan S, Mayor A, Heuschkel C, El Valy AO, von Sonnenburg F, Christophel EM: Diagnostic value of molecular markers in chloroquine-resistant falciparum malaria in Souther Mauritania. Am J Trop Med Hyg 2002, 67:449-453.

29. Lim P, Chy S, Ariey F, Incardona S, Chim P, Sem R, Denis MB, Hewitt S, Hoyer S, Socheat D, Merecreau-Puijalon O, Fandeur T: pfort polymorphism and chloroquine resistance in Plasmodium falciparu strains isolated in Cambodia. Antimicrob Agents Chemother 2003, 47:87-94.

30. Pillai DR, Labbe AC, Vanisaveth V, Hongvangthong B, Pomphida S, Inkathone S, Zhong K, Kain KC: Plasmodium falciparu malaria in Laos: chloroquine treatment outcome and predictive value of molecular markers..

31. Djimde AA, Doumbo OK, Traore $O$, Guindo AB, Kayentao $K$, Diourte $Y$, Niare-Doumbo S, Coulibaly D, Kone AK, Cissoko Y, Tekete M, Fofana B, Dicko A, Diallo DA, Wellems TE, Kwiatkowski D, Plowe CV: Clearance of drug-resistant parasites as a model for protective immunity in Plasmodium falciparu malaria. AmJTrop Med Hyg 2003, 69:558-563.

32. Schmidt KF: Inbred parasites may spur resistance. Science 1995, 269:1670.
33. Hastings IM, Mackinnon MJ: The emergence of drug-resistant malaria. Parasitology 1998, 117:411-417.

34. Joshi H, Valecha N, Verma A, Kaul A, Mallick PK, Shalini S, Prajapati SK, Sharma SK, Dev V, Biswas S, Nanda N, Malhotra MS, Subbarao SK, Dash AP. Genetic structure of Plasmodium falciparu field isolates in eastern and north-eastern India. Malar J 2007, 6:60.

35. Baruah S, Lourembam SD, Sawian CE, Baruah I, Goswami D: Temporal and spatial variation in MSP1 clonal composition of Plasmodium falciparu in districts of Assam, Northeast India. Infect Genet Evol 2009, 9:853-859.

36. Talisuna AO, Langi P, Mutabingwa TK, Van Marck E, Speybroeck N, Egwang TG, Watkins WW, Hastings IM, D'Alessandro U: Intensity of transmission and spread of gene mutations linked to chloroquine and sulphadoxinepyrimethamine resistance in falciparum malaria. Int $J$ Parasitol 2003, 33:1051-1058.

37. Urdaneta L, Lal A, Barnabe C, Oury B, Goldman I, Ayala FJ, Tibayrenc M: Evidence for clonal propagation in natural isolates of Plasmodium falciparu from Venezuela. Proc Natl Acad Sci USA 2001, 98:6725-6729.

38. Paul REL, Packer MJ, Walmsley M, Lagog M, Randford-Cartwright LC, Paru R, Day KP: Mating patterns in malaria parasite populations of Papua New Guinea. Science 1995, 269:1709-1711.

39. Klein EY, Smith DL, Boni MF, Laxminarayan R: Clinically immune hosts as a refuge for drug-sensitive malaria parasites. Malar J 2008, 7:67.

40. Sá JM, Twu O, Hayton K, Reyes S, Fay MP, Ringwald P, Wellems TE: Geographic patterns of Plasmodium falciparu drug resistance distinguished by differential responses to amodiaquine and chloroquine. Proc Natl Acad Sci USA 2009, 106:18883-18889.

41. Dittrich $S$, Alifrangis M, Stohrer JM, Thongpaseuth $V$, Vanisaveth $V$ Phetsouvanh R, Phompida S, Khalil IF, Jelinek T: Falciparum malaria in the north of Laos: the occurrence and implications of the Plasmodium falciparu chloroquine resistance transporter (pfcrt) gene haplotype SVMNT. Trop Med Int Health 2005, 10:1267-1270.

42. Alifrangis $M$, Dalgaard MB, Lusingu JP, Vestergaard LS, Staalsoe T, Jensen AT, Enevold A, Rønn AM, Khalil IF, Warhurst DC, Lemnge MM, Theander TG, Bygbjerg IC: Occurrence of the Southeast Asian/South American SVMNT haplotype of the chloroquine-resistance transporter gene in Plasmodium falciparu in Tanzania. J Infect Dis 2006, 193:1738-1741

43. Ghosh SK, Yadav RS, Sharma VP: Sensitivity status of Plasmodium falciparu to chloroquine, amodiaquine, quinine, mefloquine and sulfadoxine/ pyrimethamine in a tribal population of District Sundargarh, Orissa. Indian J Malariol 1992, 29:211-218.

44. Barkakaty BN, Das S, Deka RP, Sen T, Roy RG, Pattanayak S: Response to $600 \mathrm{mg}$ amodiaquine base with $45 \mathrm{mg}$ primaquine as presumptive treatment in chloroquine resistant Plasmodium falciparu infection in Assam. Indian J Med Res 1980, 72:191-193.

45. Pandya AP, Barkakaty BN, Narasimham MV: Comparative efficacy of chloroquine and amodiaquine in Plasmodium falciparu strain of northeastern India. J Commun Dis 1994, 26:61-67.

46. Sisowath C, Stromberg J, Martensson A, Msellem M, Obondo C, Bjorkman A, Gil JP: In viv selection of Plasmodium falciparu pfmdr1 $86 \mathrm{~N}$ coding alleles by artemetherlumefantrine (Coartem). J Infect Dis 2005, 191:1014-1017.

47. Duraisingh MT, Jones $P$, Sambou I, von Seidlein L, Pinder M, Warhurst DC: The tyrosine-86 allele of the pfmdr1 gene of Plasmodium falciparu is associated with increased sensitivity to the antimalarials mefloquine and artemisinin. Mol Biochem Parasitol 2000, 108:13-23.

48. Sisowath C, Ferreira PE, Bustamante LY, Dahlström S, Mårtensson A, Björkman A, Krishna S, Gil JP: The role of pfmdr in Plasmodium falciparu tolerance to artemether-lumefantrine in Africa. Trop Med Int Health 2007 12:736-742.

49. Valecha N, Srivastava P, Mohanty SS, Mittra P, Sharma SK, Tyagi PK, Pradhan K, Dev V, Singh R, Dash AP, Sharma YD: Therapeutic efficacy of artemether lumefantrine in uncomplicated falciparum malaria in India. Malar J 2009, 8:107.

doi:10.1186/1475-2875-11-16

Cite this article as: Mallick et al:: Mutant pfcrt "SVMNT" haplotype and wild type pfmdr1 "N86" are endemic in Plasmodium vivax dominated areas of India under high chloroquine exposure. Malaria Journal 2012 $11: 16$. 